\title{
Effects of different biochars on antibiotic resistance genes during swine manure thermophilic composting
}

\author{
Jian Wang ${ }^{1,2}$, Bin Sui ${ }^{2,3}$, Yujun Shen ${ }^{1,2}$, Haibo Meng ${ }^{1,2^{*}}$, Lixin Zhao ${ }^{2,3}$, Haibin Zhou ${ }^{1,2}$, \\ Ran $\mathrm{Li}^{1,2}$, Jingtao Ding ${ }^{1,2}$, Hongsheng Cheng ${ }^{1,2}$, Xi Zhang ${ }^{1,2}$ \\ (1. Institute of Energy and Environmental Protection, Chinese Academy of Agricultural Engineering Planning and Design, \\ Beijing 100125, China; 2. Key Laboratory of Technologies and Models for Cyclic Utilization from Agricultural Resources, \\ Ministry of Agriculture and Rural Affairs of the People's Republic of China, Beijing 100125, China; \\ 3. Chinese Academy of Agricultural Engineering Planning and Design, Beijing 100125, China)
}

\begin{abstract}
Elimination of antibiotic resistance genes (ARGs) in animal manure from concentrated animal feeding operations by thermophilic composting has drawn increasing attention. This study investigated the effects of sawdust biochar, corn stover biochar and peanut hull biochar with three spiked levels on ARGs in swine manure during thermophilic composting. Thirteen ARGs corresponding to four classes of antibiotics (tetracyclines, sulfonamides, macrolides and quinolones) were determined in the composting piles. Results indicated that the ten tested composting groups became fully mature after 30-day thermophilic composting process. tet $\mathrm{M}, t e t \mathrm{O}$ and $\operatorname{erm} \mathrm{B}$ were reduced in all tested groups; tet $\mathrm{C}$ and $t e t \mathrm{G}, \operatorname{tet} \mathrm{X}, \operatorname{sul} 1, \operatorname{sul} 2, \operatorname{erm} \mathrm{F}, \operatorname{qnr} \mathrm{D}$ and $a a c\left(6^{\prime}\right)-I b$ were mostly reduced under low level biochar addition but increased under higher level biochar addition; gyrA increased under medium biochar addition and reduced in other groups; oq $\mathrm{B}$ remained comparatively stable throughout the composting process. The addition levels of spiked biochar are more important than types of spiked biochar on the removal of ARGs in the composting pile. The average removal rates of ARGs in the control group, low, medium and high level biochar addition groups were $0.24 \mathrm{logs}, 0.52-0.72 \mathrm{logs},-0.52-0.18 \mathrm{logs}$ and $-0.19-0.21 \mathrm{logs}$, respectively. In summary, low level biochar addition could enhance the elimination of studied ARGs in swine manure during the composting process, while medium level biochar addition to the composting piles would increase the risk of ARGs' propagation.
\end{abstract}

Keywords: biochar, antibiotic resistance genes, thermophilic composting, swine manure

DOI: $10.25165 /$ j.ijabe.20181106.4667

Citation: Wang J, Sui B, Shen Y J, Meng H B, Zhao L X, Zhou H B, et al. Effects of different biochars on antibiotic resistance genes during swine manure thermophilic composting. Int J Agric \& Biol Eng, 2018; 11(6): 166-171.

\section{Introduction}

Antibiotics are widely and heavily used in Chinese livestock and poultry industries. In 2013, up to 84000 tons of veterinary antibiotics were used in China, and this amount contributed to $52 \%$ of the total antibiotic usage in China ${ }^{[1]}$. The lack of efficient treatment of animal manure resulted in high residual level of

Received date: $2018-09-21 \quad$ Accepted date: 2018-11-07

Biographies: Jian Wang, Engineer, research interests: cyclic utilization from agricultural resources, Email: wangiian@caaepd.org.cn; Bin Sui, Professor, research interests: agricultural and rural construction and cyclic utilization from agricultural resources, Email: suibin@caaepd.org.cn; Yujun Shen, Senior Engineer, research interests: cyclic utilization from agricultural resources, Email: shenyujun@caaepd.org.cn; Lixin Zhao, Professor, research interests: energy resource utilization of agricultural wastes, Email: zhaolixin@caaepd.org.cn; Haibin Zhou, Senior Engineer, research interests: treatment and utilization of agricultural wastes, Email: zhouhaibin@caaepd.org.cn; Ran Li, Assistant Engineer, research interests: fertilizer utilization of agricultural wastes, Email: liran@caaepd.org.cn; Jingtao Ding, Senior Engineer, research interests: cyclic utilization from agricultural resources, Email: dingjingtao@caaepd.org.cn; Hongsheng Cheng, Senior Engineer, research interests: fertilizer utilization of agricultural wastes, Email: chenghongsheng@caaepd.org.cn; Xi Zhang, Engineer, research interests: fertilizer utilization of agricultural wastes, Email: zhangxi@ caaepd.org.cn.

*Corresponding author: Haibo Meng, Professor, research interests: cyclic utilization from agricultural resources. Chinese Academy of Agricultural Engineering Planning and Design, No. 41, Maizidian Street, Chaoyang District, Beijing 100125, China. Tel: +86 10 59197288, Fax: +86 10 59197276, Email: menghaibo@caaepd.org.cn. antibiotics. The detected residual concentrations of antibiotics in animal manure could reach to $\mathrm{g} / \mathrm{kg} \operatorname{grade}^{[2]}$. As a result, the residual antibiotics in animal manure for growth promotion and disease control has led to the dissemination of antibiotic resistance genes (ARGs) ${ }^{[3-5]}$.

Composting, which can transform animal manure into organic fertilizer, is a commonly and widely adopted technology in China. Existing studies have shown that composting can effectively remove the antibiotics in broiler ${ }^{[6]}$ pig $^{[7,8]}$ and cow ${ }^{[9,10]}$ manure. Besides, the behaviors of ARGs during manure composting process were also studied, but the results were somewhat distinct. Although many studies reported that composting could reduce ARG levels in animal manure ${ }^{[11-13]}$, some studies showed that ARG levels were not sufficiently reduced after composting ${ }^{[14-16]}$. The reduction of ARGs may depend on temperature ${ }^{[11]}$, aerobic condition $^{[12]}$ and moisture content ${ }^{[16]}$ of the composting pile.

Biochar is a kind of solid product obtained from pyrolysis of biomass residues in the absence or deficiency of oxygen. As an additive in composting, biochar can reduce the contamination potentials of composting product, such as reducing the emissions of ammonia ${ }^{[17-19]}$, odors and greenhouse gases ${ }^{[20,21]}$, as well as deactivating the heavy metals ${ }^{[22]}$. The addition of biochar could also promote the removal of ARGs. $\mathrm{Li}$ et al. ${ }^{[23]}$ found that addition of bamboo charcoal during chicken manure composting could reduce the relative abundances of most studied ARGs by 0.85-1.15 logs. Cui et al. ${ }^{[24]}$ reposted that different biochar types (such as rice straw and mushroom biochar) and manure types (such 
as duck and swine manure) influenced the behaviors of ARGs in different ways. Sawdust, corn stover and peanut hull were abundant biomass resources for biochar production in China. However, the effects of biochars produced by the three biomass types on ARGs during manure composting still remain largely unknown.

Therefore, a series of simulated swine manure thermophilic composting tests with addition of three kinds of biochars were carried out to investigate the behaviors of tetracycline resistance genes (TRGs), sulfonamide resistance genes (SRGs), fluoroquinolone resistance genes (QRGs) and macrolide resistance genes (MRGs). The aims of this study were to investigate the effects of different types and levels of biochars addition on ARGs during swine manure composting and to evaluate the most appropriate spiked proportion of biochar addition for eliminating ARGs in the composting piles.

\section{Materials and methods}

\subsection{Composting materials}

The composting materials comprised a mixture of swine manure, corn stover (approximate $1 \mathrm{~cm}$ ), and three types of biochars (sawdust, corn stover and peanut hull biochar). Swine manure was collected from a swine farm in Shunyi District, Beijing. Corn stover was collected from the surrounding farmland in Daxing District, Beijing. Biochars were made from sawdust, corn stover and peanut hull, respectively, at a pyrolysis temperature of $600^{\circ} \mathrm{C}$. The physicochemical properties of the materials are shown in Supporting information.

\subsection{Composting operation}

Ten simulated composting groups were prepared. For each composting group, $24 \mathrm{~kg}$ of fresh manure was mixed with $3 \mathrm{~kg}$ of corn stover using a blender to adjust the final $\mathrm{C} / \mathrm{N}$ ratio to 30 and the final moisture content to $65 \%$. Biochars were spiked to the composting mixture at levels of low (6\%), medium (12\%) and high (24\%) on a dry weight basis. Ten composting groups including: Control (swine manure + corn stover), SB6 (sawdust biochar 6\%+ swine manure + corn stover), SB12 (sawdust biochar $12 \%+$ swine manure + corn stover), SB24 (sawdust biochar 24\% + swine manure + corn stover), CB6 (corn stover biochar 6\% + swine manure + corn stover), CB12 (corn stover biochar $12 \%+$ swine manure + corn stover), CB24 (corn stover biochar $24 \%+$ swine manure + corn stover), PB6 (peanut hull biochar $6 \%+$ swine manure + corn stover), PB12 (peanut hull biochar $12 \%+$ swine manure + corn stover), PB24 (peanut hull biochar $24 \%+$ swine manure + corn stover). Afterward, each tested group of composting mixture was put into a bench-scale composting bioreactor $^{[25]}$. The aeration rate of each group is $0.1 \mathrm{~m}^{3} /\left(\mathrm{min} \cdot \mathrm{m}^{3}\right)$ using an intermittent aeration mode with $5 \mathrm{~min}$ of aeration followed by $30 \mathrm{~min}$ without aeration over the whole composting process, which lasted for 30 days. Composite samples were collected by mixing three subsamples that collected from the bottom, middle and top layers of each pile on Day 0 and 30.

\subsection{DNA extraction and quantitative PCR (qPCR)}

Total DNA was extracted from $0.2 \mathrm{~g}$ of each composite sample by using a FastDNA SPIN kit for soil (MP-bio, USA). The concentration and quality of the extracted DNA were determined by spectrophotometric analysis (Genequant 1300, GE Healthcare, USA) and agarose gel electrophoresis, respectively. The extraction and analysis of DNA were performed in triplicate for each sample.

Thirteen ARGs, including five TRGs (i.e., tet $\mathrm{C}$, tet $\mathrm{G}$, tet $\mathrm{X}$, tet $\mathrm{M}$, tet $\mathrm{O}$ ), two SRGs (i.e., sul1 and sul2), four QRGs (i.e., gyrA, $q n r \mathrm{D}, a a c\left(6^{\prime}\right)-\mathrm{Ib}$ and $o q x \mathrm{~B}$ ), two MRGs (i.e., $\operatorname{erm} \mathrm{B}$ and $e r m \mathrm{~F}$ ), as well as the $16 \mathrm{~S}$ rRNA genes, were quantified using the q-PCR method. Primers used for each gene in this study were according to our former study ${ }^{[16]}$ and other studies ${ }^{[26-30]}$. The temperature program consisted of initial denaturation at $95^{\circ} \mathrm{C}$ for $30 \mathrm{~s}$, followed by 40 cycles of $15 \mathrm{~s}$ at $95^{\circ} \mathrm{C}, 20 \mathrm{~s}$ at different annealing temperatures and extension at $72^{\circ} \mathrm{C}$ for $30 \mathrm{~s}$, and finished with melt-curve analysis from $60^{\circ} \mathrm{C}$ to $95^{\circ} \mathrm{C}$. Ten-fold serial dilutions ( $10^{8}$ to 1 gene copy number) of the plasmid DNA were performed to establish the standard curve. All the $R^{2}$ of standard curve were more than 0.99. As the absolute abundance of ARGs was severely impacted by the total extracted biomass of each sample, the relative abundance of ARGs (copy number of ARG/copy number of $16 \mathrm{~S}$ rDNA) was used in this study.

\subsection{Statistical analysis}

All statistical analyses were performed using SPSS version 19.0, and the paired samples $t$-test based on the $p$-value was used to assess the homogeneity of variance with significance levels of $5 \%$ $(p<0.05)$.

\section{Results and discussion}

\subsection{Evaluation of composting maturity}

According to the US EPA standard regarding the time and temperature requirements for biosolids in-vessel composting, which is " $55^{\circ} \mathrm{C}$ for at least $3 \mathrm{~d}$ "[31], it indicates that the cumulative high temperature (i.e., cumulative temperature above $55^{\circ} \mathrm{C}$ ) is crucial for the maturity of composting piles. The cumulative high temperature of ten tested composting groups ranged from $287.4{ }^{\circ} \mathrm{C} \cdot \mathrm{d}$ to $868.5{ }^{\circ} \mathrm{C} \cdot \mathrm{d}$ and exceeded the US EPA standard $\left(165^{\circ} \mathrm{C} \cdot \mathrm{d}\right)$ (Figure 1). Compared with $\mathrm{CK}$, the addition of peanut hull biochar (PB6, PB12 and PB24) increased the value of cumulative high temperature of composting piles, while the addition of other two tested biochars showed no significant effect on cumulative high temperature. In addition, the germination indexes (GI) of ten composting groups after $30 \mathrm{~d}$ of composing were $83.1 \%-119.5 \%$, indicating the maturity of composting piles.

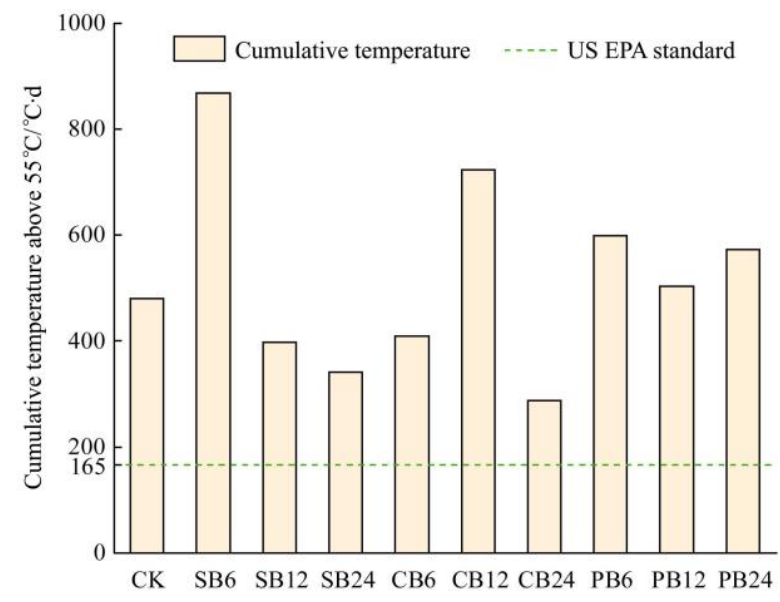

Figure 1 Cumulative temperature of composting piles

\subsection{Behaviors of TRGs}

Ribosomal protection (RP), efflux pump (EFP) and enzymatic inactivation (EI) proteins were three main mechanisms of $\mathrm{TRGs}^{[32,33]}$. In this study, two EFP TRGs (tetC and tet $\mathrm{G}$ ), two RP TRGs (tet $\mathrm{M}$ and $t e t \mathrm{O})$ and one EI TRG $($ tet $\mathrm{X})$ were determined in the tested composting groups. The variation of their relative abundances was presented in Figure 2. The log-transformed removals of ARGs were calculated based on their relative 
abundances in the raw and composted piles. During the composting process, the relative abundance of TRGs in the tested composting groups varied from $1.25 \times 10^{-4}-1.42 \times 10^{-1}$ in the beginning to $2.75 \times 10^{-6}-1.42 \times 10^{-2}$ in the end, and the log-transformed removals of TRGs were $-1.93-2.35$ logs. RP TRGs were removed in all tested groups by 0.61-2.35 logs. Higher addition of sawdust biochar could enhance the removal of RP TRGs $(p<0.05)$. Comparatively, EFP TRGs and EI TRG were mostly removed by $-1.85-1.06$ logs in SB6, CB6 and PB6, but increased in other tested groups by $-0.39-1.93$ logs. It was reported that the hosts of RP TRGs were mainly anaerobic bacteria and prone to diminish during aerobic composting, while the hosts of EFP and EI TRGs were most commonly aerobic and facultative Gram-negative bacteria ${ }^{[16,32]}$. Thus, RP TRGs were more likely to be eliminated than EFP and EI TRGs after aerobic composting. The addition of biochar could increase the duration of the thermophilic phase; on the other hand, with the specialty of structure and nutrients, biochar is a suitable habitat and carbon source for microbial communities ${ }^{[34]}$. Hence, low level addition $(6 \%)$ of biochar may enhance the thermophilic effect of composting piles to kill some heat-liable bacteria then foster the ARGs elimination, while high level addition (12\% and 24\%) of biochar to composting piles could better promote the microbial proliferation and lead to the propagation of ARGs they carried.
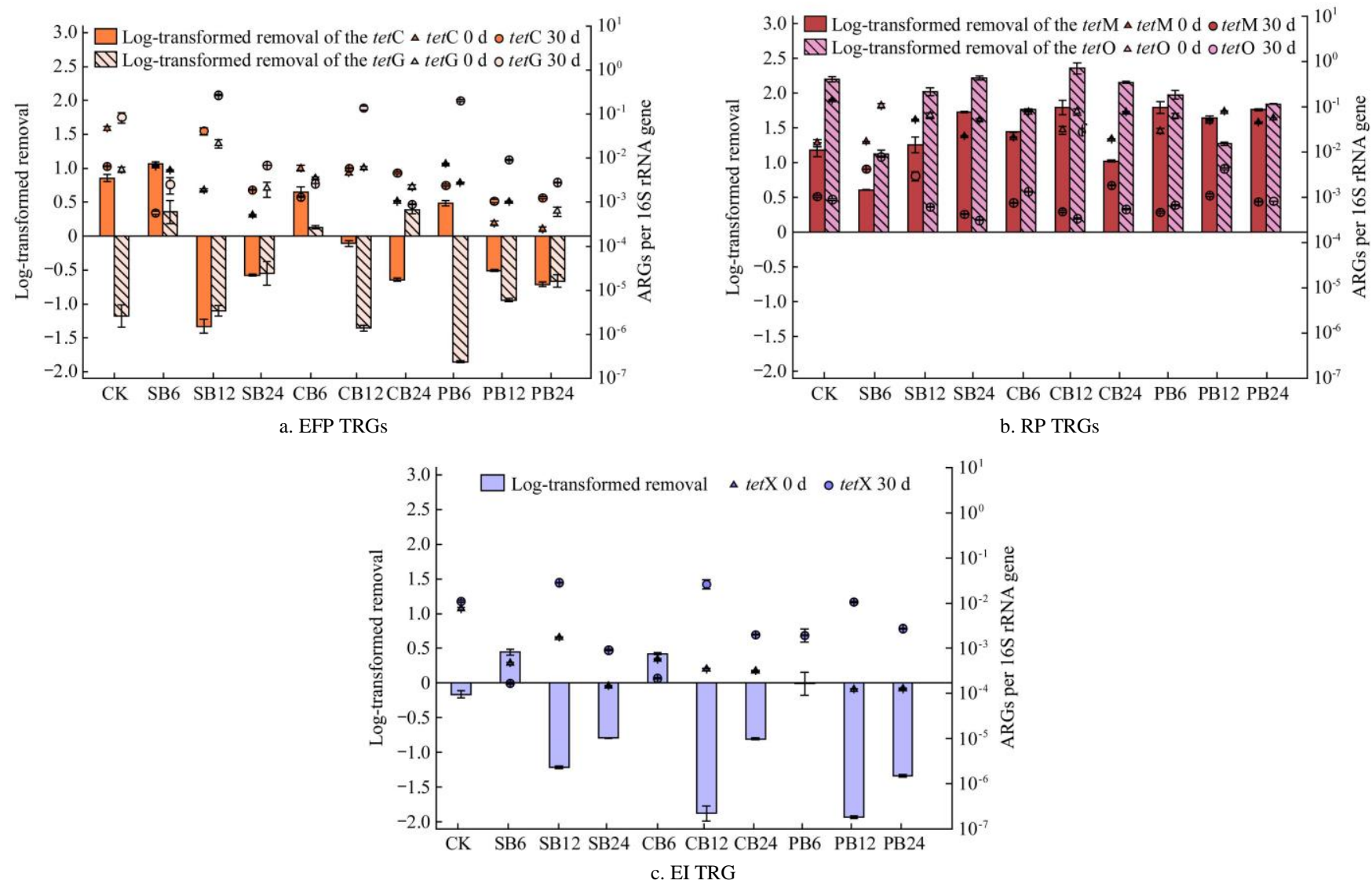

Figure 2 Log-transformed removal and relative abundances of EFP TRGs, RP TRGs and EI TRGs in the composting piles

\subsection{Behaviors of SRGs and MRGs}

The mutant dihydropteroate synthase (DHPS) genes are the main sulfonamide resistance gene type. sul1 and sul2 were most commonly mutant DHPS genes ${ }^{[35]}$. Figure 3a presented the variation of SRGs in the tested composting groups. The relative abundance of tested SRGs varied from $1.16 \times 10^{-4}-8.61 \times 10^{-2}$ at the beginning of composting to $1.53 \times 10^{-4}-7.79 \times 10^{-2}$ in the end, and the log-transformed removals of SRGs were $-1.54-0.42$ logs. Results in this study showed that the addition of biochars led to an overall increment of sul 1 by $-0.02-1.08$ logs; similarly, sul 2 were reduced by $0.15-0.42$ logs only under low level biochar addition (6\%) but increased by $0.65-1.54$ logs under high level biochar addition $(12 \%$ and $24 \%$ ). As sul1 and sul2 are often associated with mobile gene elements such as plasmids and integrons, their dissemination could be very efficient ${ }^{[35]}$, indicating that they are more recalcitrant to the microbial communities evolution during composting than other chromosome-borne ARGs. Thus, as the addition of biochars could enhance the microbial activities in the tested composting groups, the relative abundance of SRGs would also be increased along with this process.

The erm genes were important MRGs related to macrolide-lincosamide-streptogramin B antibiotic multi-resistance phenotype ${ }^{[36]}$, and often related to transposons. The variation of erm $\mathrm{B}$ and erm $\mathrm{F}$ in the tested composting groups were shown in Figure $3 \mathrm{~b}$. During the composting process, the relative abundance of them varied from $9.40 \times 10^{-4}-8.28 \times 10^{-2}$ in the beginning to $2.00 \times 10^{-5}-3.65 \times 10^{-3}$ in the end, and their $\log$-transformed removals were $-1.34-2.57 \operatorname{logs}$. Similar to the behaviors of SRGs, erm $\mathrm{B}$ and erm $\mathrm{F}$ were reduced by $0.5-2.41$ logs under low level biochar addition $(6 \%)$. However, when the dose of biochars increased, ermB was reduced by 1.20-2.57 logs while erm $\mathrm{F}$ was increased by $-0.02-1.34 \operatorname{logs}$, manifesting opposite variation patterns. erm $\mathrm{B}$ is commonly related to Tn1545 and Tn916 conjugative transposons ${ }^{[37]}$, and ermF is often related to Tn5030 conjugative transposon ${ }^{[38]}$. A previous study found that ermF was highly transferable among clinical anaerobic and aerobic bacteria ${ }^{[39]}$. The different gene location might influence their behaviors. 

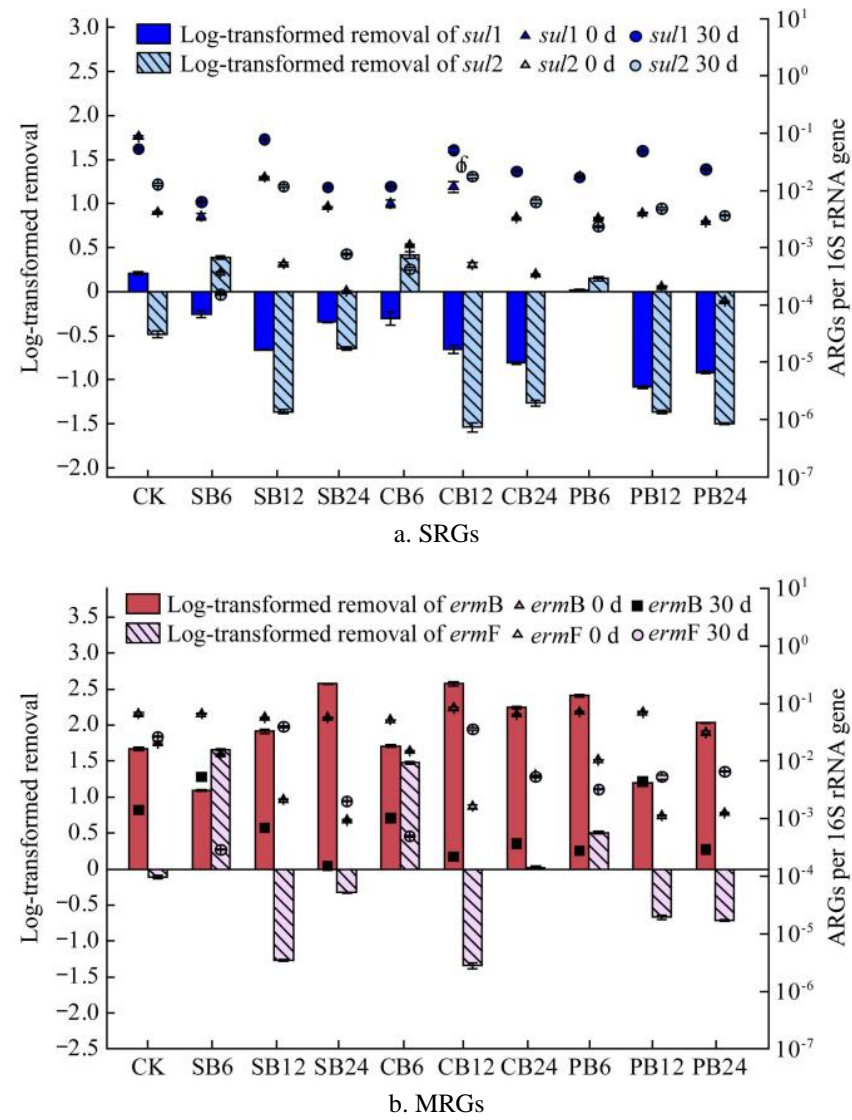

Figure 3 Log-transformed removal and relative abundances of SRGs and MRGs in the composting piles

\subsection{Behaviors of the quinolone resistance genes}

Target-mediated (TM) QRG (i.e. gyrA) and plasmid-mediated (PM) QRGs (i.e. oqxB, $q n r \mathrm{D}$ and $a a c\left(6^{\prime}\right)-I b$ ) were determined in this study. Figure 4 showed the profiles of QRGs in the tested composting groups. Compared with other ARGs, the variations of different QRGs showed distinct patterns. The relative abundance of gyrA ranged from $5.71 \times 10^{-4}-2.77 \times 10^{-2}$ at the beginning of composting to $3.41 \times 10^{-4}-1.61 \times 10^{-2}$ when the composting was finished (Figure 4a). gyrA decreased by 0.29-0.69 logs in SB6, SB24, CB6, CB24 and PB6, and increased by 0.42-1.33 logs in CK, $\mathrm{SB} 12, \mathrm{CB} 12, \mathrm{~PB} 12$ and $\mathrm{PB} 24$. oq $x \mathrm{~B}$ was relatively stable in all tested group with the relative abundance of $1.79 \times 10^{-3}-8.41 \times 10^{-3}$, and increased by $0.11-0.43$ logs in the nine biochar-added groups (Figure 4b). In comparison, qnrD and aac( $\left.6^{\prime}\right)-I b$ decreased by 0.46-1.33 logs in under low level biochar addition (6\%), and mostly increased by $0.12-2.48$ logs under high level biochar addition (12\% and 24\%) (Figure 4c). The dramatic differences of QRGs' variations could be attributed to many reasons. It seemed that medium dosage of biochars (12\%) could foster the propagation of $g y r$ A. A possible explanation may be that $g y r$ A is usually chromosome-borne ARG and proliferates depending on its host bacteria, moderate dosage of biochars (12\%) might facilitate the reproduction of its host. oqx $\mathrm{B}$ was reported to be highly abundant in swine wastewater from Beijing, China ${ }^{[40]}$. In addition, the plasmids carrying oq $x \mathrm{~B}$ were proved to be of high mobility, which could promote their maintenance and transmissibility ${ }^{[41]}$. Thus, this might contribute to the stability of $o q x \mathrm{~B}$ during the composting. $q n r \mathrm{D}$ and $a a c\left(6^{\prime}\right)-I b$ are also located on plasmids but their variations were different from that of $o q x \mathrm{~B}$, probably because that $o q x \mathrm{~B}$ is located on larger plasmids which may limit their dissemination between different species or general of bacteria ${ }^{[27]}$, while unlike $o q x \mathrm{~B}, q n r \mathrm{D}$ and $a a c\left(6^{\prime}\right)-I b$ are often located on smaller plasmids that could propagate by the active microbial activities during composting ${ }^{[42,43]}$.
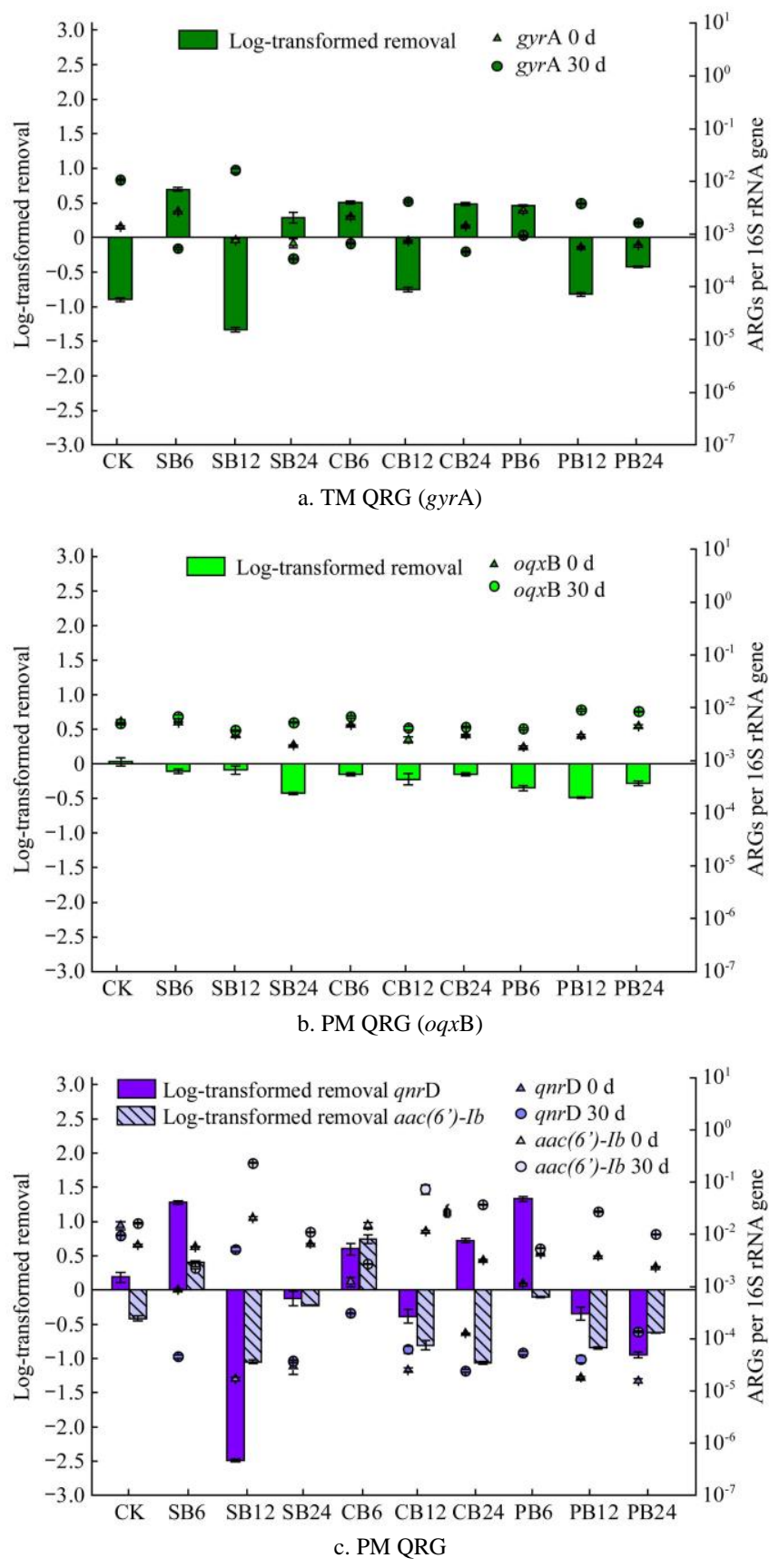

Figure 4 Log-transformed removal and relative abundances of QRGs $g y r \mathrm{~A}, o q x \mathrm{~B}, q n r \mathrm{D}$ and $a a c\left(6^{\prime}\right)-I b$ in the composting piles

\subsection{Evaluation of ARGs' removal by different biochars}

The overall log-transformed removals of thirteen ARGs were presented in Figure 5. The average values of log-transformed removal in the ten tested groups were $-0.52-0.72 \operatorname{logs}$ and there was no significant difference among different biochar types. It is clear from the figure that the average removal rates of ARGs in groups of low level biochar addition (SB6, CB6 and PB6) were the highest compared with other groups, which were $0.67,0.72$ and 0.52 logs, respectively, and the rate of CB6 was higher than that of CK $(0.24 \operatorname{logs})$ at significant level $(p<0.05)$. Groups of medium level biochar addition (SB12, CB12 and PB12) achieved the lowest average removal rates of ARGs $(-0.52-0.18 \operatorname{logs})$, of which the rates of SB12 and PB12 were lower than that of CK at extremely significant level $(p<0.01)$. Groups of high level biochar addition 
(SB24, CB24 and PB24) achieved the medium average removal rates of ARGs (-0.19-0.21 logs). Few studies had evaluated the effects of various biochars under different spiked levels on the removal of ARGs during thermophilic composting. Cui et al. ${ }^{[44]}$ evaluated the addition of rice straw biochar and mushroom biochar on the behaviors of ARGs during chicken manure composting and found that the addition of the two biochars achieved opposite effects on the ARGs, which may be due to their different influences on the bacterial communities. Duan et al. ${ }^{[45]}$ also reported that the bacterial community succession caused by biochar addition was the main mechanism that affected the variations of ARGs and int $\mathrm{I} 1$ in soil amendment. Our results showed that the spiked levels of biochars affected the removal of ARGs more significantly than the types of biochars. As the proliferation of ARGs were mainly depending on the reproduction of their host bacteria, their different behaviors in the test groups may also due to the changes of bacterial communities affected by different types and levels of biochars, which needs further study.

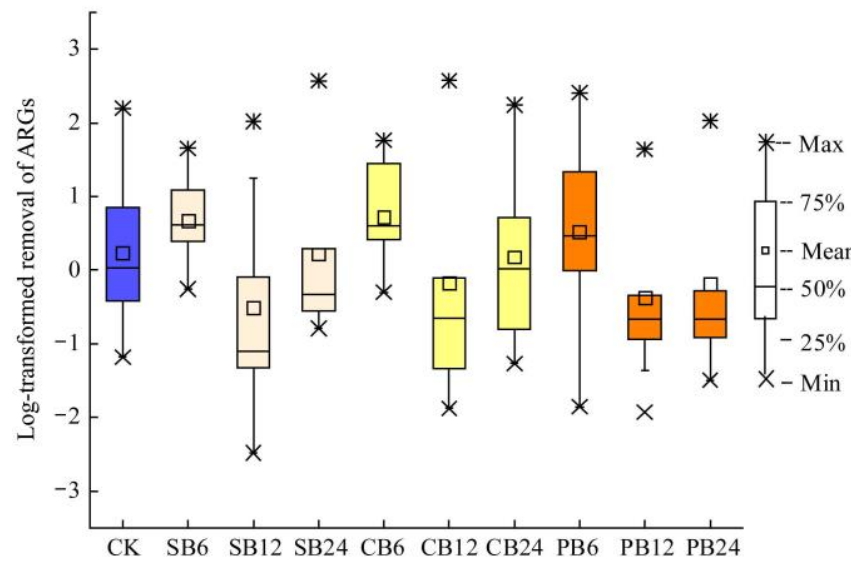

Figure 5 Distribution of log-transformed removals of tested ARGs in the composting piles

\section{Conclusions}

In this study, a series of simulated swine manure thermophilic composting tests with addition of three kinds and three spiked levels of biochars were carried out to investigate the variations of four classes of ARGs. Based on the experimental results, the following conclusions can be drawn:

Ten tested composting groups became fully mature after 30 days. RP TRGs (tet $\mathrm{M}$ and tet $\mathrm{O}$ ) were reduced in all tested groups. EFP TRGs (tetC and tetG), EI TRG (tetX), SRGs (sul1 and sul2) and two PM QRGs ( $q n r \mathrm{D}$ and $\left.a a c\left(6^{\prime}\right)-\mathrm{Ib}\right)$ were mostly reduced under low level biochar addition $(6 \%)$ but increased under higher level biochar addition (12\% and 24\%). MRGs (ermB and ermF) were reduced under low level biochar addition but behaved the opposite variation patterns under higher level biochar addition. TM QRG ( $g y r \mathrm{~A})$ was promoted under medium biochar addition and reduced in other groups. PM QRG (oq $x \mathrm{~B})$ remained comparatively stable throughout the composting. Spiked levels of biochars are more important than types of biochars added to the composting piles on the removal of ARGs. Low level biochar addition could enhance the removal of ARGs, while medium level biochar addition would foster the propagation of ARGs.

\section{Acknowledgement}

The project was financially supported by the National Key R\&D Program of China (2017YFD0800800).

\section{[References]}

[1] Zhang Q Q, Ying G G, Pan C G, Liu Y S, Zhao J L. A comprehensive evaluation of antibiotics emission and fate in the river basins of China: source analysis, multimedia modelling, and linkage to bacterial resistance. Environmental Science \& Technology, 2015; 49(11): 6772-6782.

[2] Zhao L, Dong Y H, Wang H. Residues of veterinary antibiotics in manures from feedlot livestock in eight provinces of China. Science of the Total Environment, 2010; 408(5): 1069-1075.

[3] Wang J, Ben W W, Yang M, Zhang Y, Qiang Z M. Dissemination of veterinary antibiotics and corresponding resistance genes from a concentrated swine feedlot along the waste treatment paths. Environment International, 2016; 92-93: 317-323.

[4] He L Y, Liu Y S, Su H C, Zhao J L, Liu S S, Chen J, et al. Dissemination of antibiotic resistance genes in representative broiler feedlots environments: Identification of indicator ARGs and correlations with environmental variables. Environmental Science \& Technology, 2014; 48(22): 13120-13129.

[5] He L Y, Ying G G, Liu Y S, Su H C, Chen J, Liu S S, et al. Discharge of swine wastes risks water quality and food safety: Antibiotics and antibiotic resistance genes from swine sources to the receiving environments. Environment International, 2016; 92-93: 210-219.

[6] Ho Y B, Zakaria M P, Latif P A, Saari N. Degradation of veterinary antibiotics and hormone during broiler manure composting. Bioresource Technology, 2013; 131: 476-484.

[7] Kim K R, Owens G, Ok Y S, Park W K, Lee D B, Kwon S I. Decline in extractable antibiotics in manure-based composts during composting. Waste Management, 2012; 32(1): 110-116.

[8] Selvam A, Zhao Z Y, Wong J W C. Composting of swine manure spiked with sulfadiazine, chlortetracycline and ciprofloxacin. Bioresource Technology, 2012; 126: 412-417.

[9] Arikan O A, Sikora L J, Mulbry W, Khan S U, Foster G D. Composting rapidly reduces levels of extractable oxytetracycline in manure from therapeutically treated beef calves. Bioresource Technology, 2007; 98(1): 169-176.

[10] Arikan O A, Mulbry W, Rice C. Management of antibiotic residues from agricultural sources: use of composting to reduce chlortetracycline residues in beef manure from treated animals. Journal of Hazardous materials, 2009; 164(2-3): 483-489.

[11] Qian X, Sun W, Gu J, Wang X J, Zhang Y J, Duan M L, et al. Reducing antibiotic resistance genes, integrons, and pathogens in dairy manure by continuous thermophilic composting. Bioresource Technology, 2016; 220: 425-432.

[12] Wang L L, Oda Y, Grewal S, Morrison M, Michel F, Yu Z T. Persistence of resistance to erythromycin and tetracycline in swine manure during simulated composting and lagoon treatments. Microbial Ecology, 2012; 63(1): 32-40.

[13] Selvam A, Xu D L, Zhao Z Y, Wong J W C. Fate of tetracycline, sulfonamide and fluoroquinolone resistance genes and the changes in bacterial diversity during composting of swine manure. Bioresource Technology, 2012; 126: 383-390.

[14] Qian X, Gu J, Sun W, Wang X J, Su J Q, Stedfeld R. Diversity, abundance, and persistence of antibiotic resistance genes in various types of animal manure following industrial composting. Journal of Hazardous materials, 2018; 344: 716-722.

[15] Esperón F, Delgado M M, Iglesias I, Carballo M, Ugarte-Ruíz M, Moreno $\mathrm{M}$ Á, et al. Evaluation of tetracycline resistance genes during avian manure composting process. International Journal of Infectious Diseases, 2016; 53: 44.

[16] Wang J, Ben W W, Zhang Y, Yang M, Qiang Z M. Effects of thermophilic composting on oxytetracycline, sulfamethazine, and corresponding resistance genes in swine manure. Environmental Science: Processes \& Impacts, 2015; 17: 1654-1660.

[17] Malińska K, Zabochnicka-Świątek M, Dach J. Effects of biochar amendment on ammonia emission during composting of sewage sludge. Ecological Engineering, 2014; 71: 474-478.

[18] Chen Y X, Huang X D, Han Z Y, Huang X, Hu B, Shi D Z, et al. Effects of bamboo charcoal and bamboo vinegar on nitrogen conservation and heavy metals immobility during pig manure composting. Chemosphere, 2010; 78(9): 1177-1181.

[19] Dias B O, Silva C A, Higashikawa F S, Roig A, Sánchezmonedero M A Use of biochar as bulking agent for the composting of poultry manure: effect on organic matter degradation and humification. Bioresource Technology, 2010; 101(4): 1239-1246. 
[20] Chowdhury M A, De N A, Jensen L S. Potential of aeration flow rate and bio-char addition to reduce greenhouse gas and ammonia emissions during manure composting. Chemosphere, 2014; 97(1): 16-25.

[21] Sánchezgarcía M, Alburquerque J A, Sánchezmonedero M A, Roig A, Cayuela M L. Biochar accelerates organic matter degradation and enhances $\mathrm{N}$ mineralisation during composting of poultry manure without a relevant impact on gas emissions. Bioresource Technology, 2015; 192: 272-279.

[22] Awasthi M K, Wang Q, Huang H, Li R H, Shen F, Lahori A H, et al. Effect of biochar amendment on greenhouse gas emission and bio-availability of heavy metals during sewage sludge co-composting. Journal of Cleaner Production, 2016; 135: 829-835.

[23] Li H C, Duan M L, Gu J, Zhang Y J, Qian X, Ma J, et al. Effects of bamboo charcoal on antibiotic resistance genes during chicken manure composting. Ecotoxicology and Environmental Safety, 2017; 140: 1-6.

[24] Cui E, Wu Y, Jiao Y, Zuo Y, Rensing C, Chen H. The behavior of antibiotic resistance genes and arsenic influenced by biochar during different manure composting. Environmental Science and Pollution Research, 2017; 24(16): 14484-14490.

[25] Shen Y J, Zhao L X, Meng H B, Hou Y Q, Zhou H B, Wang F, et al. Effect of aeration rate, moisture content and composting period on availability of copper and lead during pig manure composting. Waste Management \& Research, 2016; 34(6): 578-583.

[26] Kugelberg E, Löfmark S, Wretlind B, Andersson D I. Reduction of the fitness burden of quinolone resistance in Pseudomonas aeruginosa. Journal of Antimicrobial Chemotherapy, 2005; 55(1): 22-30.

[27] Mu Q H, Li J, Sun Y X, Mao D Q, Wang Q, Luo Y. Occurrence of sulfonamide-, tetracycline-, plasmid-mediated quinolone- and macrolide-resistance genes in livestock feedlots in Northern China. Environmental Science and Pollution Research, 2014; 22(9): 1-9.

[28] Park C H, Robicsek A, Jacoby G A, Sahm D, Hooper D C. Prevalence in the United States of $a a c\left(6^{\prime}\right)-I b-c r$ encoding a ciprofloxacin-modifying enzyme. Antimicrobial Agents and Chemotherapy, 2006; 50(11): 3953-3955.

[29] Kim H B, Wang M H, Park C H, Kim E C, Jacoby G A, Hooper D C. oq $x \mathrm{AB}$ encoding a multidrug efflux pump in human clinical isolates of Enterobacteriaceae. Antimicrobial Agents and Chemotherapy, 2009; 53(8): 3582-3584

[30] Chen J, Yu Z T, Jr F C M, Wittum T, Morrison M. Development and application of real-time PCR assays for quantification of erm genes conferring resistance to macrolides-lincosamides-streptogramin $\mathrm{B}$ in livestock manure and manure management systems. Applied and Environmental Microbiology, 2007; 73(14): 4407-4416.

[31] USEPA. Use of Composting for Biosolids Management. https://www.epa.gov/biosolids/use-composting-biosolids-management. August, 2018.

[32] Roberts M C. Acquired tetracycline resistance genes. In: Dougherty TJ,
Pucci MJ editors. Antibiotic Discovery and Development. New York: Springer US; 2012. pp. 543-568.

[33] Thaker M, Spanogiannopoulos P, Wright G. The tetracycline resistome. Cellular and Molecular Life Sciences, 2010; 67(3): 419-431.

[34] Xiao R, Awasthi M K, Li R H, Park J, Pensky S M, Wang Q, et al Recent developments in biochar utilization as an additive in organic solid waste composting: A review. Bioresource Technology, 2017; 246: 203-213.

[35] Sköld O. Sulfonamide resistance: mechanisms and trends. Drug Resistance Updates, 2000; 3(3): 155-160.

[36] Vester B, Douthwaite S. Macrolide resistance conferred by base substitutions in $23 \mathrm{~S}$ rRNA. Antimicrobial Agents and Chemotherapy, 2001; 45(1): 1-12.

[37] [37] Okitsu N, Kaieda S, Yano H, Nakano R, Hosaka Y, Okamoto R, et al. Characterization of ermB gene transposition by $\mathrm{Tn} 1545$ and $\mathrm{Tn} 917$ in macrolide-resistant Streptococcus pneumoniae isolates. Journal of Clinical Microbiology, 2005; 43(1): 168-173.

[38] Chung W O, Young K, Leng Z T, Roberts M C. Mobile elements carrying erm $\mathrm{F}$ and tet $\mathrm{Q}$ genes in Gram-positive and Gram-negative bacteria. Journal of Antimicrobial Chemotherapy, 1999; 44(3): 329-335.

[39] Chung W O, Werckenthin C, Schwarz S, Roberts M C. Host range of the ermF rRNA methylase gene in bacteria of human and animal origin. Journal of Antimicrobial Chemotherapy, 1999; 43(1): 5-14.

[40] Li J, Wang T, Shao B, Shen J Z, Wang S C, Wu Y N. Plasmid-mediated quinolone resistance genes and antibiotic residues in wastewater and soil adjacent to swine feedlots: potential transfer to agricultural lands. Environmental Health Perspectives, 2012; 120(8): 1144-1149.

[41] Zhao J J, Chen Z L, Chen S, Deng Y T, Liu Y H, Tian W, et al Prevalence and dissemination of oqx $\mathrm{AB}$ in Escherichia coli Isolates from animals, farmworkers, and the environment. Antimicrobial Agents and Chemotherapy, 2010; 54(10): 4219-4224.

[42] Casin I, Bordon F, Bertin P, Coutrot A, Podglajen I, Brasseur R, et al. Aminoglycoside 6'-n-acetyltransferase variants of the $\mathrm{Ib}$ type with altered substrate profile in clinical isolates of Enterobacter cloacae and Citrobacter freundii. Antimicrobial Agents and Chemotherapy, 1998; 42(2): 209-215.

[43] Cavaco L M, Hasman H, Xia S, Aarestrup F M. qnrD, a novel gene conferring transferable quinolone resistance in Salmonella enterica serovar kentucky and bovismorbificans strains of human origin. Antimicrobial Agents and Chemotherapy, 2009; 53(2): 603-608.

[44] Cui E P, Wu Y, Zuo Y R, Chen H. Effect of different biochars on antibiotic resistance genes and bacterial community during chicken manure composting. Bioresource Technology, 2016; 203: 11-17.

[45] Duan M L, Li H C, Gu J, Tuo X X, Sun W, Qian X, et al. Effects of biochar on reducing the abundance of oxytetracycline, antibiotic resistance genes, and human pathogenic bacteria in soil and lettuce. Environmental Pollution, 2017; 224: 787-795. 